\title{
Dynamic Response and Failure Mechanism of Layered Thin Plate Rock Mass Under Sustained Dynamic Load
}

Feng Li ( $\sim$ lifengcumtb@126.com )

China University of Mining and Technology-Beijing

Chuang Chen

China University of Mining and Technology-Beijing

Yue Zhang

China National Offshore Oil Corporation (China)

\section{Xin Zhao}

China University of Mining and Technology-Beijing

\section{Xinhui Dong}

China University of Mining and Technology-Beijing

Runchuan Sun

China University of Mining and Technology-Beijing

\section{Research Article}

Keywords: Sustained dynamic load, layered thin plate rock mass, vibration characteristics, dynamic damage and failure

Posted Date: August 9th, 2021

DOI: https://doi.org/10.21203/rs.3.rs-754576/v1

License: (c) (1) This work is licensed under a Creative Commons Attribution 4.0 International License. Read Full License 


\title{
Dynamic Response and Failure Mechanism of Layered Thin
}

\section{Plate Rock Mass under Sustained Dynamic Load}

\author{
Feng $\mathrm{Li}^{*}{ }^{1,2}$, Chuang Chen ${ }^{2}$, Yue Zhang ${ }^{3}$, Xin Zhao ${ }^{2}$, Xinhui Dong ${ }^{2}$, Runchuan Sun ${ }^{2}$ \\ (1. State Key Laboratory for Geomechanics and Deep Underground Engineering, China University of Mining and \\ Technology(Beijing),Beijing,100083;2.School of Emergency Management and Safety Engineering, China \\ University of Mining and Technology(Beijing),Beijing, 100083;3. CNOOC Research Institute Ltd, Beijing \\ 100028)
}

Abstract: Based on the dual equation of Hamilton system and Duhamel's integral, and the orthogonality of the deflection equations, the mechanical model of homogeneous rectangular thin plate rock mass was established. And the results showed that the effective vibration modes of thin plate granite with four sides fixed were the $1^{\text {st }}, 5^{\text {th }}$ and $6^{\text {th }}$ orders under uniform dynamic load, and their vibration frequencies were $310 \mathrm{rad} / \mathrm{s}, 975 \mathrm{rad} / \mathrm{s}$ and $1309 \mathrm{rad} / \mathrm{s}$ respectively. Under sustained dynamic load, moreover, the change of the vibration state of the $1^{\text {st }}$ mode was the most sharp, and the positive and negative alternation of its amplitude was the most frequent in the whole period, which had the most obvious effect on the vibration of the thin plate rock mass. Based on the Fourier transform formula, the Fourier series expressions and waveforms of sustained dynamic loads which contained rectangular wave, triangular wave and impact wave were obtained. The vibration characteristics of thin plate rock mass under these three kinds of sustained dynamic loads, the dynamic distribution of deflection, stress and maximum shear stress, as well as the dynamic damage and failure modes were all obtained. The results showed that plate cracks occurred firstly in the middle of the four sides and these cracks would propagate rapidly along the boundary of the thin plate rock mass; and then, plate cracks occurred at the central of the thin plate and the main develop tendency of these cracks was outward along the long central axis, moreover, these cracks also tended to expand outward along the short side central axis. It could be concluded that the initial failure position of the thin plate rock mass could be determined by the $1^{\text {st }}$ effective mode, and the development direction and trend of the damage could be determined by $5^{\text {th }}$ and $6^{\text {th }}$ effective vibration modes; under sustained dynamic load, tensile-shear failure occurred at four sides and shear failure at four corners; The tensile failure occurred in the central area of the thin plate, which developed into a main crack along the central long axis and a secondary crack along the short central axis, forming an " O-十" fracture pattern.

Keywords: Sustained dynamic load, layered thin plate rock mass, vibration characteristics, dynamic damage and failure 


\section{Introduction}

The sedimentary process and the arrangement of mineral particles during the formation of coal measure rock mass make it have obvious bedding structure and show layered structure macroscopically ${ }^{[1-3]}$. This layered rock mass widely exists in mining, construction, transportation and water conservancy projects ${ }^{[4-6]}$. Moreover, coal and rock dynamic disaster , such as coal and gas outburst, rockburst, rock fall and spalling, is often accompanied by slabbing and spalling, as shown in Fig. $1^{[7-8]}$.
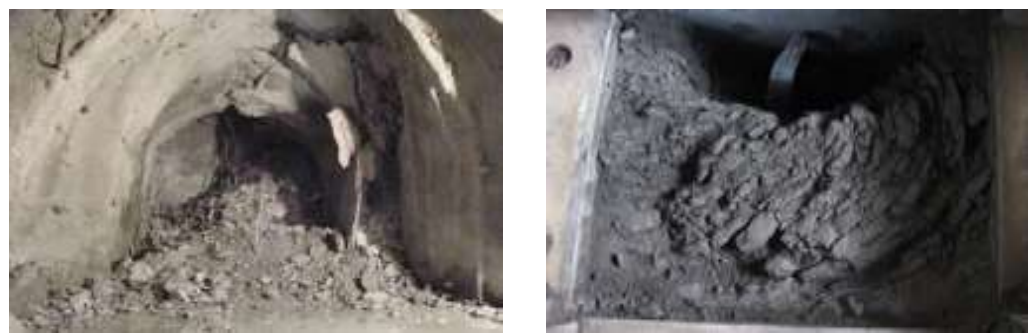

Fig. 1 Spalling in rockburst and coal and gas outburst

Fairhurst et al. firstly described the plate crack failure in detail which is approximately parallel to the wall of surrounding rock, and called it spalling or slabbing ${ }^{[9]}$. The results of true triaxial mechanical tests of hard rock such as marble show that the failure mode of rock gradually changes from shear failure to plate crack failure with the increase of intermediate principal stress ${ }^{[10]}$. The main failure modes of rock mass in deep mining are slab cracking spalling and rockburst under unloading conditions, which can be divided into four types: tensile plate crack rockburst, shear rockburst, tensile plate crack spalling and shear spalling ${ }^{[11]}$. Moreover, the slab cracking spalling often presents cracks like onion skin which densely distribute in the surrounding rock of tunnel wall ${ }^{[12]}$.

Therefore, the model of thin plate rock mass has been used widely to reveal the mechanism and process of coal and rock dynamic disaster in deep mining where coal and gas outburst, rockburst, rockfall and chamber instability are prone to occur. Based on the thin plate model, the analytical formulas were established of critical stress and displacement of surrounding rock in the range of splitting under high ground stress ${ }^{[13]}$; and with the energy dissipation analysis method, the failure mechanism of rock column instability after macro splitting crack was studied, the critical load of rock plate buckling failure was obtained, and the calculation formula of the number of splitting cracks was derived ${ }^{[14]}$. Plate cracking failure in coal rock dynamic disaster can be defined as a series of macro cracks parallel to the excavation boundary of rock mass in deep mining, which is a precursor of rockburst in hard rock, and a mechanical model of orthotropic thin plate was established for plate cracking rock mass (Fig. 2) ${ }^{[15-16]}$.

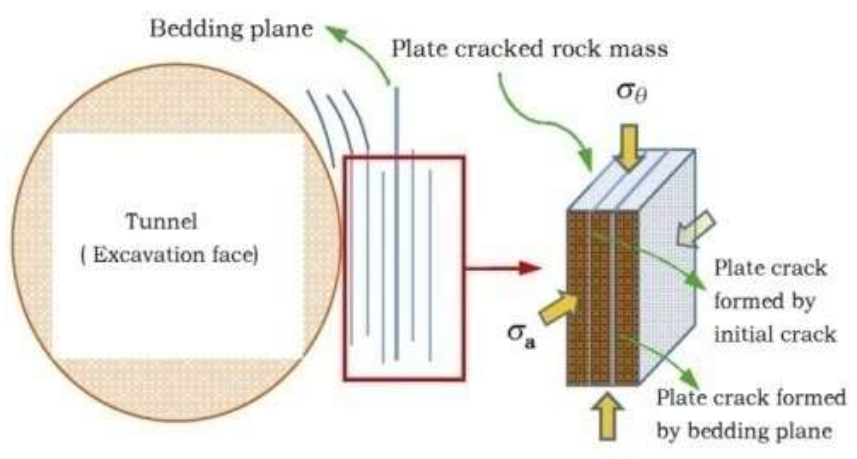

Fig. 2 Slabbing in hard $\operatorname{rock}^{[16]}$ 
From this, it could be seen that many scholars have deeply conducted the mechanism and mechanical behavior of plate cracking failure and plate cracking rockburst under static load. But, in the whole dynamic process of mining, and during the beginning, formation, development and termination of coal and rock dynamic disaster, rock mass would bear the dynamic disturbances from mine earthquake, such as blasting, roof and floor breaking, rock instability and so on. And the vibration of rock mass under these dynamic disturbances has a significant impact on its mechanical properties ${ }^{[17-19]}$. At present, the researches on dynamic mechanical response characteristics are only in the stage of experimental exploration, and the mechanisms of dynamic damage, failure and disaster-causing are still unclear ${ }^{[20-22]}$.

In this paper, based on the dual equation of Hamilton system and Duhamel's integral, and the orthogonality of the deflection equations, the mechanical model of homogeneous rectangular thin plate rock mass was established to study the effective vibration modes and frequencies of layered thin plate rock mass under dynamic loads. Based on the Fourier transform formula, the Fourier series expressions and waveforms of sustained dynamic loads were obtained, which contained rectangular wave, triangular wave and impact wave. And the vibration characteristics of thin plate rock mass under these three kinds of sustained dynamic loads, the dynamic distribution of deflection, stress and maximum shear stress, as well as the dynamic damage and failure modes were obtained. Based on the third strength criterion and numerical simulation results, the initial position, development trend and the final distribution of plate cracks were analyzed, which is of great significance to reveal the dynamic damage process and mechanism of rock mass and control coal and rock dynamic disasters.

\section{Deflection Equation of the Thin Plate Rock Mass under Forced Vibration}

In this study, the assumptions were as follows: the rectangular plates of thin rock mass were transversely isotropic in mechanics; the density of the thin plate was $\rho$; the thickness was $h$; the size was $a \times b$; the elastic modulus was E; and the Poisson's ratio was $v$. The specific forms of the deflection of thin plate rock mass under free vibration may be as follows ${ }^{[23-24]}$ :

$$
\begin{aligned}
& W(x)=a_{1} e^{i \beta_{1} x}+b_{1} e^{-i \beta_{1} x}+c_{1} e^{\beta_{2} x}+d_{1} e^{-\beta_{2} x}=A_{1} \cos \beta_{1} x+B_{1} \sin \beta_{1} x+C_{1} \cosh \beta_{2} x+D_{1} \sinh \beta_{2} x \\
& W(y)=a_{2} e^{i \alpha_{1} y}+b_{2} e^{-i \alpha_{1} y}+c_{2} e^{\alpha_{2} y}+d_{2} e^{-\alpha_{2} y}=A_{2} \cos \alpha_{1} y+B_{2} \sin \alpha_{1} y+C_{2} \cosh \alpha_{2} y+D_{2} \sinh \alpha_{2} y
\end{aligned}
$$

Where, $W$ is the deflection mode function; $\alpha_{1}$ and $\alpha_{2}$ are characteristic values in the $x$ direction; $\beta_{1}$ and $\beta_{2}$ are characteristic values in the $y$ direction. The Parameters $\alpha_{1}, \alpha_{2}, \beta_{1}, \beta_{2}$ meet the following rules:

$$
\alpha_{1}^{2}+\alpha_{2}^{2}=\beta_{1}^{2}+\beta_{2}^{2}=2 k^{2}, \alpha_{1}^{2}+\beta_{1}^{2}=k^{2}, \alpha_{2}^{2}+\beta_{2}^{2}=3 k^{2}, \quad \alpha_{2}^{2}-\beta_{1}^{2}=k^{2}
$$

It could be considered that the rock mass nearby excavation surface is composed of layers of thin plate rock mass with four sides fixed (C-C-C-C), and the deflection and frequency equations of the

\begin{tabular}{|c|c|c|c|c|}
\hline \multicolumn{2}{|c|}{$\begin{array}{l}\text { thin plate rock } \\
\text { mass }\end{array}$} & & frequency equations & $\begin{array}{c}\text { deflection equations } \\
\qquad W(x, y)\end{array}$ \\
\hline $\boldsymbol{A}$ & $C$ & & \multirow{2}{*}{$\begin{array}{l}x \text { direction: } \\
\frac{1-\cos \beta_{1} a \cosh \beta_{2} a}{\sin \beta_{1} a \sinh \beta_{2} a}=\frac{\beta_{1}^{2}-\beta_{2}^{2}}{2 \beta_{1} \beta_{2}}\end{array}$} & \multirow{2}{*}{$\begin{array}{l}x \text { direction: } \\
W(x)=-\cos \beta_{1} x+\frac{\beta_{2}}{\beta_{1}} k_{2} \sin \beta_{1} x+\cosh \beta_{2} x-k_{2} \sinh \beta_{2} x\end{array}$} \\
\hline \multirow{2}{*}{$C$} & \multirow{2}{*}{\multicolumn{2}{|c|}{$c$}} & & \\
\hline & & & $\begin{array}{l}y \text { direction: } \\
\qquad \underline{1-\cos \alpha_{1} b \cosh \alpha_{2} b}=\frac{\alpha_{1}^{2}-\alpha_{2}^{2}}{}\end{array}$ & $\begin{array}{l}y \text { direction: } \\
W(y)=-\cos \alpha y+\frac{\alpha_{2}}{2} k_{1} \sin \alpha y+\cosh \alpha_{y} y-k_{1} \sinh \alpha_{1} y\end{array}$ \\
\hline & $C$ & & $\sin \alpha_{1} b \sinh \alpha_{2} b \quad 2 \alpha_{1} \alpha_{2}$ & $\alpha_{1}$ \\
\hline
\end{tabular}
thin plate rock mass may be shown in Tab.1 ${ }^{[23]}$.

Tab. 1 Deflection and frequency equations of the thin plate rock mass under different boundary conditions 


\begin{tabular}{|l|l}
\hline (C-C-C-C) & $k_{1}=\frac{\cos \alpha_{1} b-\cosh \alpha_{2} b}{\frac{\alpha_{2}}{\alpha_{1}} \sin \alpha_{1} b-\sinh \alpha_{2} b}, k_{2}=\frac{\cos \beta_{1} a-\cosh \beta_{2} a}{\frac{\beta_{2}}{\beta_{1}} \sin \beta_{1} a-\sinh \beta_{2} a}$ \\
\hline
\end{tabular}

The solutions' form of the deflection under forced vibration can be expressed as follows:

$$
w(x, y, t)=\sum_{n=1}^{\infty} W_{n}(x, y) \varphi_{m}(t)
$$

Based on Duhamel' Integral, the solutions of $\varphi_{\mathrm{m}}(\mathrm{t})$ can be expressed as follows ${ }^{[25]}$ :

$$
\varphi_{m}(t)=\frac{1}{M_{m} \omega_{m}} \int_{0}^{t} P_{m}(\tau) \sin \omega_{m}(t-\tau) d \tau
$$

Where $\omega_{\mathrm{m}}$ is the natural frequency.

\section{Effective vibration modes of the thin plate rock mass $\mathrm{C}-\mathrm{C}-\mathrm{C}-\mathrm{C}$ under sustained dynamic load}

Taking granite in a mine in $\mathrm{Si}$ Chuan, the parameter values of the thin plate rock mass were as follows: $h=0.06 \mathrm{~m}, \rho=2800 \mathrm{~kg} / \mathrm{m}^{3}, \mathrm{E}=72 \times 10^{9} \mathrm{~Pa}, v=0.3$, and $a \times b=3 \mathrm{~m} \times 3.6 \mathrm{~m}$. Based on the frequency equation (11) of the thin plate rock mass with four sides fixed support C-C-C-C, the effective vibration modes were also solved by Newton's iterative method. The calculated results of the first 10 order vibration parameters under free vibration were shown in Tab. 2.

Tab. 2 The first 10 vibration parameters of the thin plate rock mass under free vibration (C-C-C-C)

\begin{tabular}{|c|c|c|c|c|c|c|c|c|c|c|}
\hline Parameter & $1^{\text {st }}$ order & $2^{\text {nd }}$ order & $3^{\text {rd }}$ order & $4^{\text {th }}$ order & $5^{\text {th }}$ order & $6^{\text {th }}$ order & $7^{\text {th }}$ order & $8^{\text {th }}$ order & $9^{\text {th }}$ order & $10^{\text {th }}$ order \\
\hline$\beta_{1}$ & 1.443 & 1.301 & 2.573 & 2.483 & 1.227 & 3.643 & 2.404 & 3.589 & 2.346 & 2.346 \\
\hline$\beta_{2}$ & 2.145 & 3.247 & 2.949 & 3.765 & 4.437 & 3.895 & 4.802 & 4.514 & 5.930 & 5.930 \\
\hline$\alpha_{1}$ & 1.122 & 2.104 & 1.019 & 2.001 & 3.015 & 0.975 & 2.940 & 1.935 & 3.904 & 3.851 \\
\hline$\alpha_{2}$ & 2.329 & 2.795 & 3.778 & 4.042 & 3.479 & 5.243 & 4.494 & 5.433 & 4.248 & 5.083 \\
\hline$k$ & 1.828 & 2.474 & 2.767 & 3.189 & 3.255 & 3.771 & 3.797 & 4.078 & 4.079 & 4.509 \\
\hline
\end{tabular}

Based on the Fourier transform formula, the Fourier series expressions and waveforms of sustained dynamic loads which contained rectangular wave, triangular wave and impact wave could be obtained. The FFT series expression and transformed waveforms of sustained dynamic load with amplitude $\mathrm{A}=1$ and period $\mathrm{T}=2 \mathrm{~s}$ were shown in Tab. 3 . When we inserted the Fourier series expressions into equation (4), the time harmonic vibration term $\varphi_{\mathrm{m}}(\mathrm{t})$ of thin plate rock mass under sustained rectangular wave, triangular wave and impact wave could be obtained, as shown in Tab. 4. And then, the vibration equation of thin plate rock mass under sustained dynamic load could be obtained with equation (3).

Tab. 3 The Fourier series expressions and waveforms of sustained dynamic loads $(q(t))$

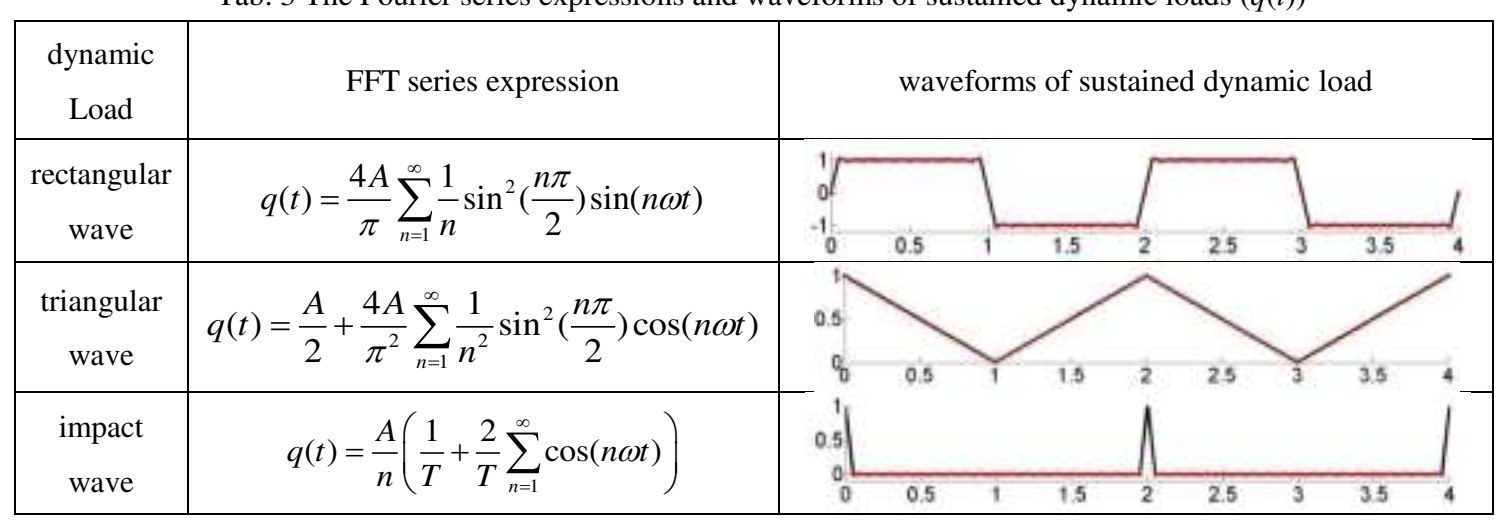

Tab.4 The time harmonic vibration term of thin plate rock mass under sustained dynamic load 


\begin{tabular}{|c|c|c|}
\hline $\begin{array}{c}\text { dynamic } \\
\text { Load }\end{array}$ & \multicolumn{2}{|c|}{ The time harmonic vibration term $\varphi_{\mathrm{m}}(\mathrm{t})$} \\
\hline $\begin{array}{c}\text { rectangular } \\
\text { wave }\end{array}$ & $\varphi_{m}(t)=\frac{4 A A_{m}}{\pi} \sum_{n=1}^{\infty} \frac{1}{n} \sin ^{2}\left(\frac{n \pi}{2}\right) \frac{n \omega \sin \left(\omega_{m} t\right)-\omega_{m} \sin (n \omega t)}{n^{2} \omega^{2}-\omega_{m}{ }^{2}}$ & \multicolumn{2}{|l|}{ 中: } \\
\hline $\begin{array}{c}\text { triangular } \\
\text { wave }\end{array}$ & $\varphi_{m}(t)=A A_{m}\left[\frac{1-\cos \left(\omega_{m} t\right)}{2 \omega_{m}}-\frac{4 \omega_{m}}{\pi^{2}} \sum_{n=1}^{\infty} \frac{1}{n^{2}} \sin ^{2}\left(\frac{n \pi}{2}\right) \frac{\cos (n \omega t)-\cos \left(\omega_{m} t\right)}{n^{2} \omega^{2}-\omega_{m}{ }^{2}}\right]$ & $A_{m}=\frac{M_{n} \omega_{m}}{A_{m}}$ \\
\hline $\begin{array}{c}\text { impact } \\
\text { wave }\end{array}$ & $\varphi_{m}(t)=\frac{A A_{m}}{\pi}\left[\frac{1-\cos \left(\omega_{m} t\right)}{2 n \omega_{m} / \omega}-\frac{\omega \omega_{m}}{n} \sum_{n=1}^{\infty} \frac{\cos (n \omega t)-\cos \left(\omega_{m} t\right)}{n^{2} \omega^{2}-\omega_{m}{ }^{2}}\right]$ & \\
\hline
\end{tabular}

The calculated results of coefficient $-A_{m}$ of the first ten orders vibration under sustained dynamic load were shown in Tab. 5, from which it could be concluded that the $1^{\text {st }}, 5^{\text {th }}$ and $6^{\text {th }}$ orders were effective vibration modes, and their natural frequencies were 308rad/s, 975rad/s, and 1309rad/s, respectively.

Tab. 5 The first ten orders' vibration modes of the thin plate rock mass under sustained dynamic load (C-C-C-C)

\begin{tabular}{|c|c|c|c|c|}
\hline Order & $w_{\mathrm{m}}(\mathrm{rad} / \mathrm{s})$ & $M_{\mathrm{m}}$ & $\iint_{\Omega} W_{m}(x, y) d x d y$ & $A_{m}$ \\
\hline $\mathbf{1}^{\text {st }}$ order & $\mathbf{3 0 8}$ & $\mathbf{5 . 7 8 7} \times \mathbf{1 0}^{\mathbf{3}}$ & $\mathbf{1 3 . 5 8 9}$ & $\mathbf{7 . 6 2 4} \times \mathbf{1 0}^{-\mathbf{6}}$ \\
\hline $2^{\text {nd }}$ order & 563 & $7.293 \times 10^{3}$ & $8.1 \times 10^{-12}$ & $1.973 \times 10^{-18}$ \\
\hline $3^{\text {rd }}$ order & 705 & $1.310 \times 10^{4}$ & $7.0 \times 10^{-12}$ & $7.581 \times 10^{-19}$ \\
\hline $4^{\text {th }}$ order & 936 & $6.482 \times 10^{3}$ & 0 & 0 \\
\hline $\mathbf{5}^{\text {th }}$ order & $\mathbf{9 7 5}$ & $\mathbf{1 . 2 6 7 \times 1 0 ^ { 4 }}$ & $\mathbf{8 . 5 0 3}$ & $\mathbf{6 . 8 8 3} \times \mathbf{1 0}^{-\mathbf{7}}$ \\
\hline $\mathbf{6}^{\text {th }}$ order & $\mathbf{1 3 0 9}$ & $\mathbf{2 . 5 8 7} \times \mathbf{1 0}^{\mathbf{4}}$ & $\mathbf{1 2 . 5 6 5}$ & $\mathbf{3 . 7 1}^{\mathbf{1 0}}$ \\
\hline $7^{\text {th }}$ order & 1328 & $6.584 \times 10^{-7}$ & $-4.3 \times 10^{-11}$ & $-4.918 \times 10^{-18}$ \\
\hline $8^{\text {th }}$ order & 1531 & $9.105 \times 10^{3}$ & $3.1 \times 10^{-9}$ & $2.798 \times 10^{-16}$ \\
\hline $9^{\text {th }}$ order & 1532 & $2.071 \times 10^{4}$ & $4.9 \times 10^{-10}$ & $1.544 \times 10^{-17}$ \\
\hline $10^{\text {th }}$ order & 1872 & $8.215 \times 10^{3}$ & 0 & 0 \\
\hline
\end{tabular}

\section{Dynamic response of the thin plate rock mass under sustained dynamic load}

Because the frequency value $w_{\mathrm{m}}$ obtained by theoretical calculation was not accurate, based on the waveform of each effective vibration modes, we found the optimal frequency values of order $1^{\text {st }}$, $5^{\text {th }}$ and $6^{\text {th }}$ were $310 \mathrm{rad} / \mathrm{s}, 975 \mathrm{rad} / \mathrm{s}$ and $1309 \mathrm{rad} / \mathrm{s}$, respectively.

4.1 Dynamic response of the thin plate rock mass under sustained rectangular wave

4.1.1 Vibration laws of $\varphi_{\mathrm{m}}(\mathrm{t})$ under sustained rectangular wave

Under sustained rectangular wave, the time harmonic vibration term $\varphi_{\mathrm{m}}(\mathrm{t})$ of effective modes about the $1^{\text {st }}, 5^{\text {th }}$ and $6^{\text {th }}$ orders were analyzed and their vibration patterns were shown in Fig. 3 . 

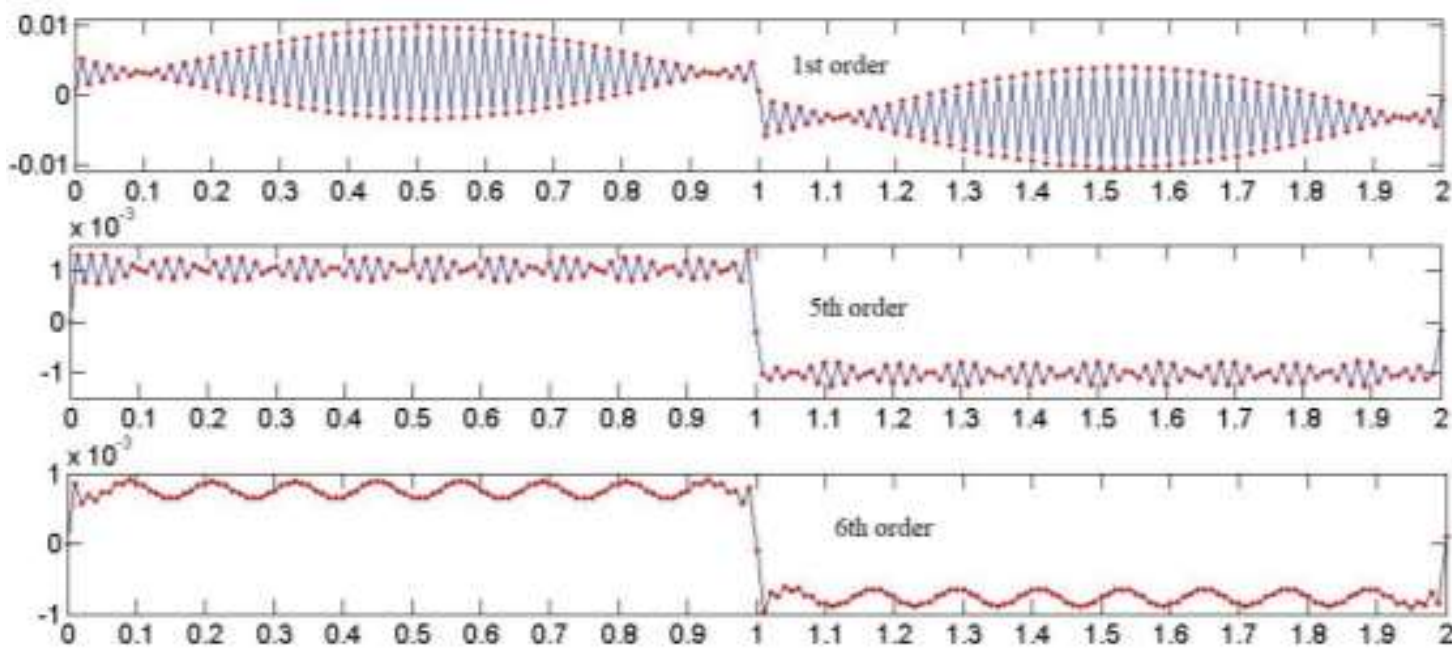

Fig. 3 the vibration of $\varphi_{\mathrm{m}}(\mathrm{t})$ of effective modes $\left(1^{\text {st }}, 5^{\text {th }}\right.$ and $6^{\text {th }}$ orders $)$ under sustained rectangular wave

It could be seen that: (1) the vibration periods of effective vibration modes about the $1^{\text {st }}, 5^{\text {th }}$ and $6^{\text {th }}$ orders of thin plate rock mass were all $2 \mathrm{~s}$, and the vibration patterns conformed to the rectangular distribution law, which were consistent with the input rectangular wave waveform; (2) the amplitude of the 1st mode was the largest which took about $0.5 \mathrm{~s}$ to reach the peak, and the maximum amplitude of the 1 st mode was larger than that of the $5^{\text {th }}$ and $6^{\text {th }}$ modes by one order of magnitude; (3) the change of the 1st mode vibration state was the most sharp, and the positive and negative alternation of its amplitude was the most frequent in the whole period, which had the most obvious effect on the vibration of the thin plate rock mass.

4.1.2 Deflection dynamic distribution of effective vibration modes of the thin plate rock mass It could be seen from the vibration law of the $1^{\text {st }}$ mode in Fig. 3 that the positive and negative peak of the $1^{\text {st }}$ order amplitude appeared at about $0.5 \mathrm{~s}$ and $1.5 \mathrm{~s}$. Therefore, we took $0.5 \mathrm{~s}, 1.5 \mathrm{~s}$ and their adjacent time points $(0.49 \mathrm{~s}$ and $1.51 \mathrm{~s})$ as typical time points to analyze their vibration state, and drew the deflection dynamic distribution of the $1^{\text {st }}$ mode of the thin plate rock mass at the typical time, as shown in Fig. 4. It could be obtained that the areas with large deflection mainly concentrated in the central area of the thin plate rock mass, and presented a symmetrical distribution along the long and short central axis.
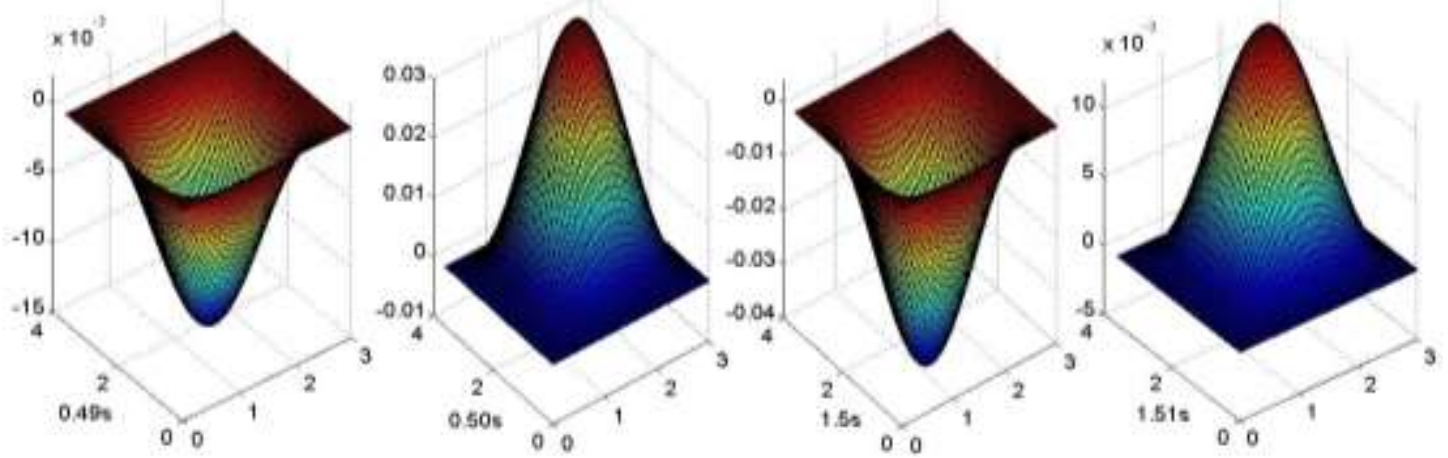

Fig. 4 Deflection dynamic distribution of the $1^{\text {st }}$ mode at the typical time

If we took vibration state at the typical time $0.5 \mathrm{~s}$ and $1.5 \mathrm{~s}$ of the $5^{\text {th }}$ and $6^{\text {th }}$ modes in Fig. 3 , the deflection dynamic distributions of which were shown in Fig. 5. It could be seen that: (1) the deflections of the $5^{\text {th }}$ and $6^{\text {th }}$ modes were symmetrically distributed about the short central axis and the long central axis respectively; (2) the deflection distribution of the $5^{\text {th }}$ mode mainly 
concentrated in the area of the long central axis, and that of the $6^{\text {th }}$ mode in the area of the short central axis.

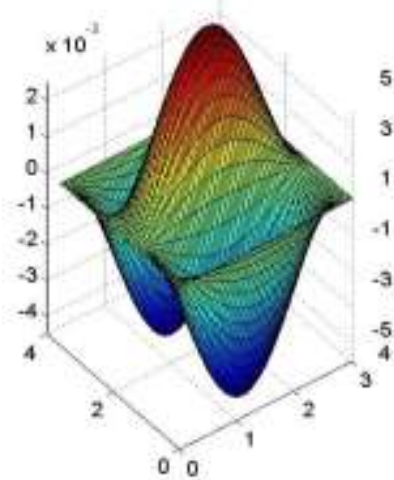

(a) Deflection of $5^{\text {th }}$ at $0.5 \mathrm{~s}$

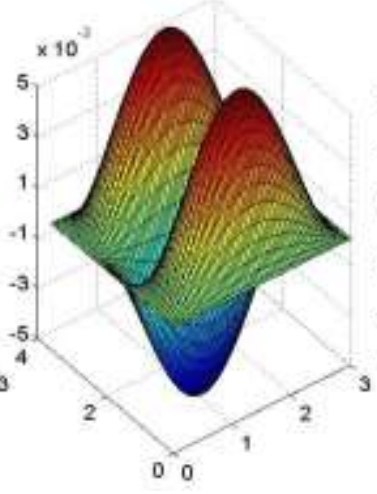

(b) Deflection of $5^{\text {th }}$ at $1.5 \mathrm{~s}$

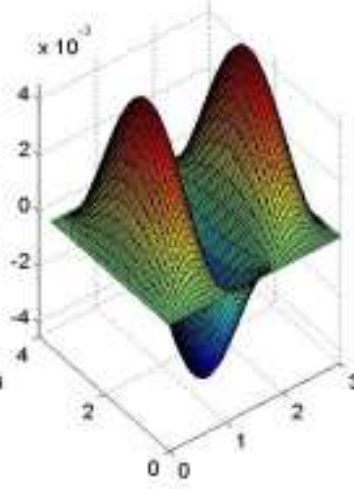

(c) Deflection of $6^{\text {th }}$ at $0.5 \mathrm{~s}$

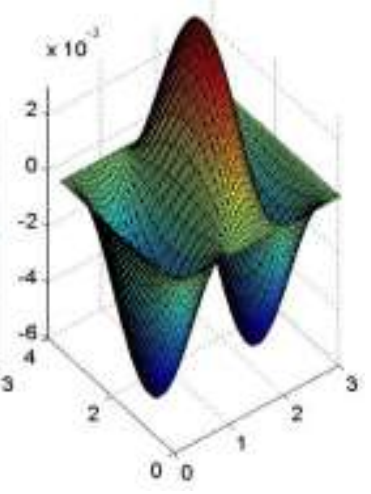

(d) Deflection of $6^{\text {th }}$ at $1.5 \mathrm{~s}$

Fig. 5 Deflection dynamic distribution of the $5^{\text {th }}$ and $6^{\text {th }}$ modes at the typical time

4.1.3 The stress dynamic distribution of effective vibration modes of the thin plate rock mass

Taking the vibration state of typical time points $0.49 \mathrm{~s}, 0.5 \mathrm{~s}, 1.5 \mathrm{~s}$ and $1.51 \mathrm{~s}$ respectively, the stress dynamic distribution of the $1^{\text {st }}$ mode of the thin plate rock mass could be shown in Fig. 6. It could be concluded that: (1) the stress $\left(\sigma_{\mathrm{x}}\right)$ concentrated areas were mainly distributed in the center of the thin plate and the two long sides, which were symmetrical along the short center axis; (2) the stress $\left(\sigma_{\mathrm{y}}\right)$ concentrated areas were mainly distributed in the central of the thin plate and the two short sides, which were symmetrical along the long central axis; (3) the stress $\left(\tau_{\mathrm{xy}}\right)$ concentrated areas were mainly distributed in the four corners of the thin plate, which were symmetrical along the two diagonals, and the stress symbols of the corners corresponding to the two diagonals were opposite.

$\boldsymbol{\sigma}_{\mathbf{x}}$
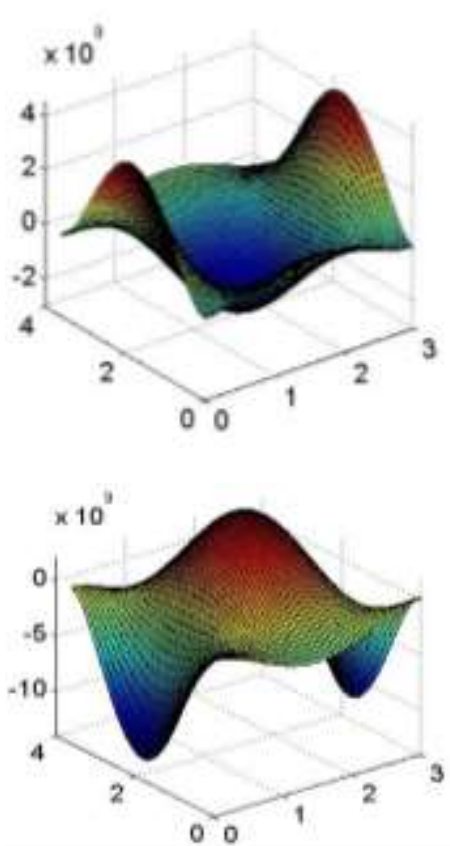

$\sigma_{\mathbf{y}}$

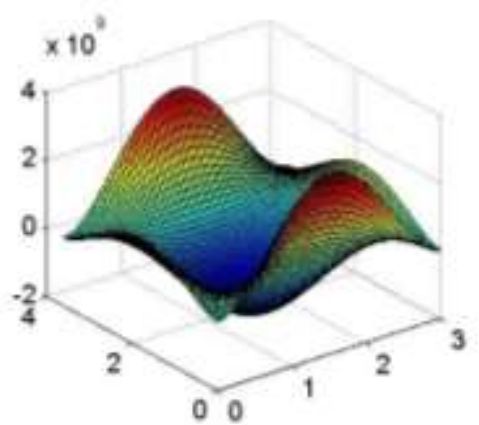

(a) The stress dynamic distribution at $0.49 \mathrm{~s}$

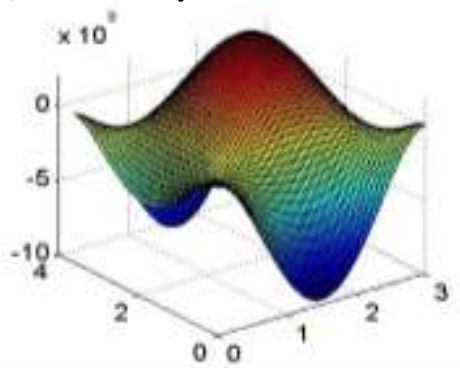

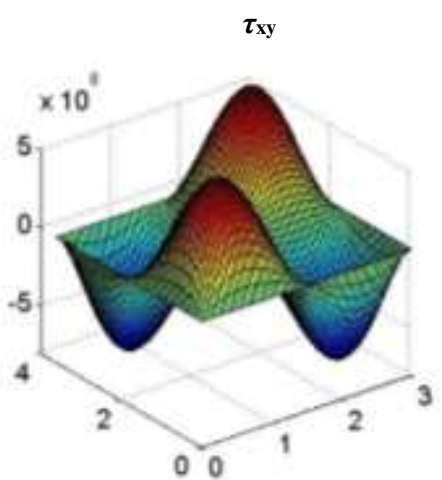

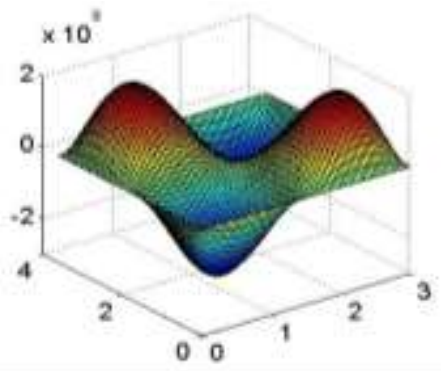

(b) The stress dynamic distribution at $0.5 \mathrm{~s}$ 

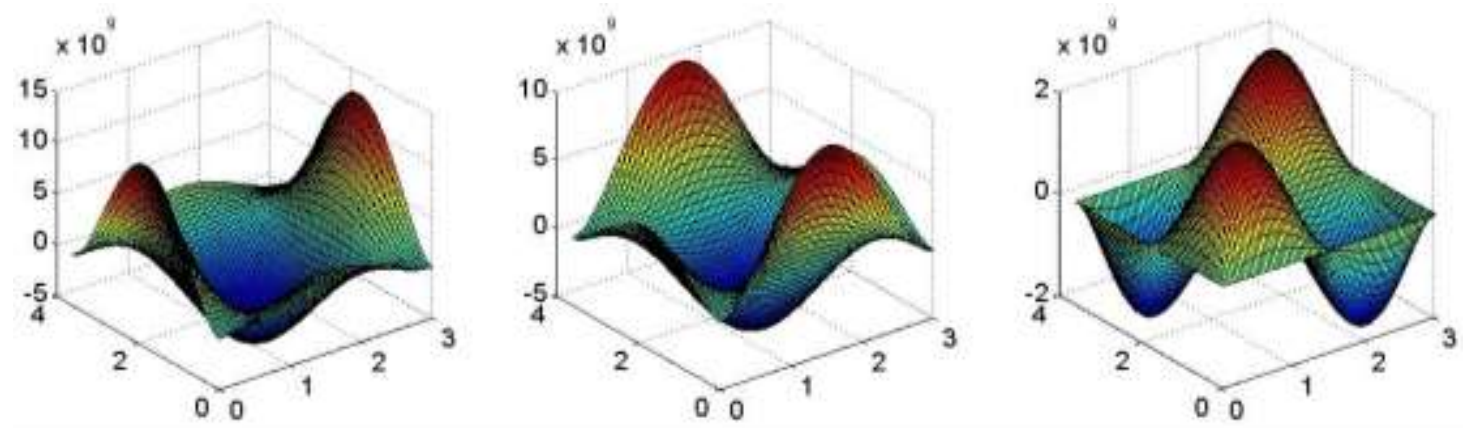

(c) The stress dynamic distribution at $1.5 \mathrm{~s}$
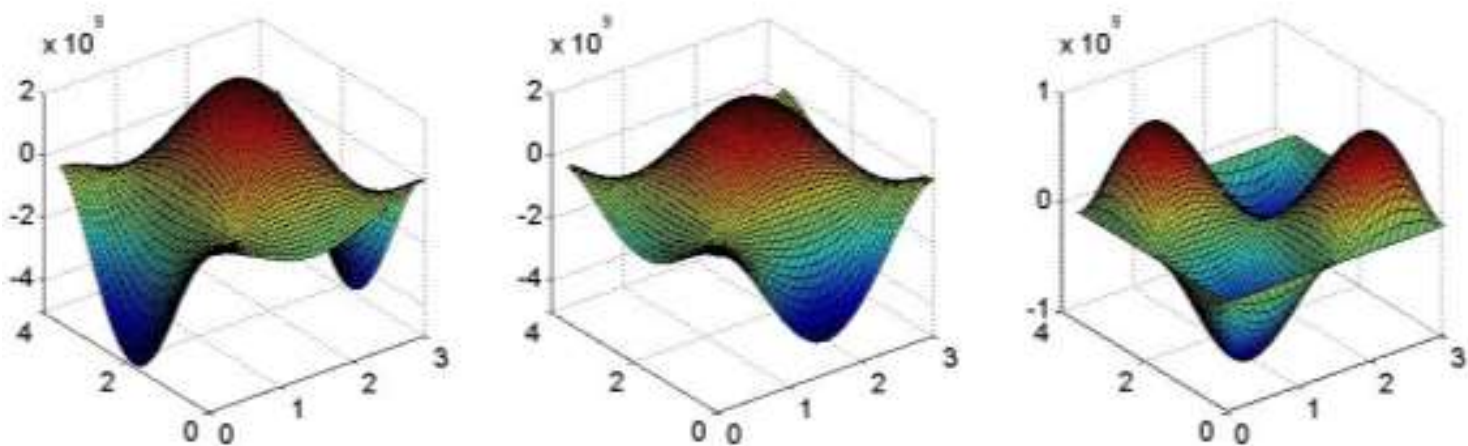

(d) The stress dynamic distribution at $1.51 \mathrm{~s}$

Fig. 6 The stress dynamic distribution of the $1^{\text {st }}$ mode at typical time

Similarly, the stress dynamic distribution of the $5^{\text {th }}$ mode of thin plate rock mass was drawn by taking the vibration state of typical time points $0.5 \mathrm{~s}$ and $1.5 \mathrm{~s}$ respectively, as shown in Fig. 7. It could be seen that: (1) the stress $\left(\sigma_{x}\right)$ mainly concentrated in four corners, long central axis and the middle of the four sides of thin plate, which were symmetrical along the long center axis; (2) and the stress $\left(\sigma_{y}\right)$ concentrated areas were mainly distributed in the middle of the two short sides and the long central axis, which were symmetrical along the long central axis; (3) the stress $\left(\tau_{x y}\right)$ concentrated areas were mainly distributed in the four corners and the middle of two long sides.
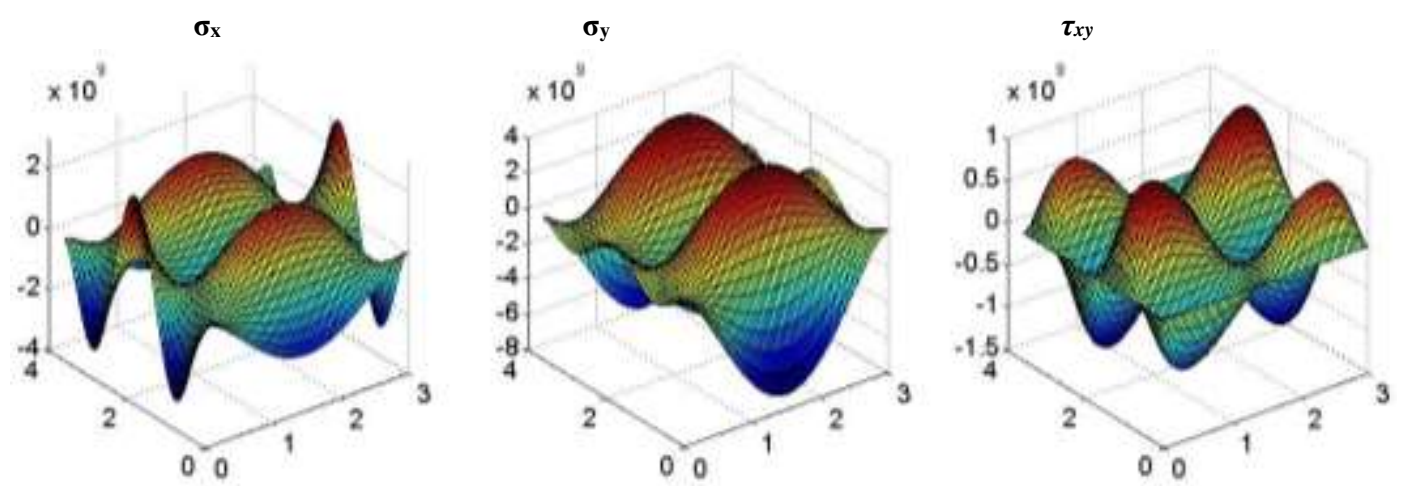

(a) The stress dynamic distribution at $0.5 \mathrm{~s}$ 

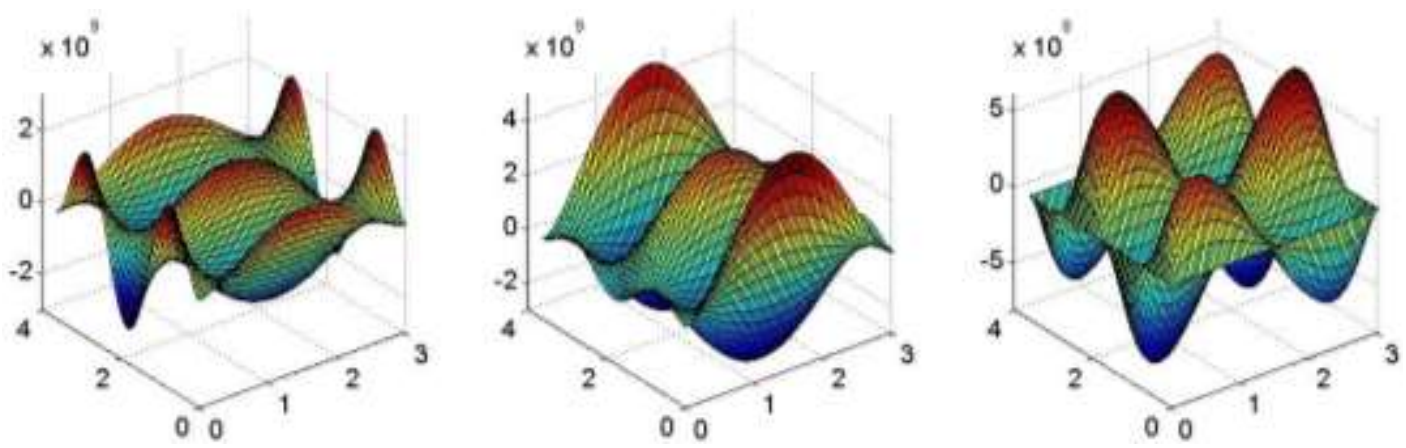

(b) The stress dynamic distribution at $1.5 \mathrm{~s}$

Fig. 7 The stress dynamic distribution of the $5^{\text {th }}$ mode at typical time
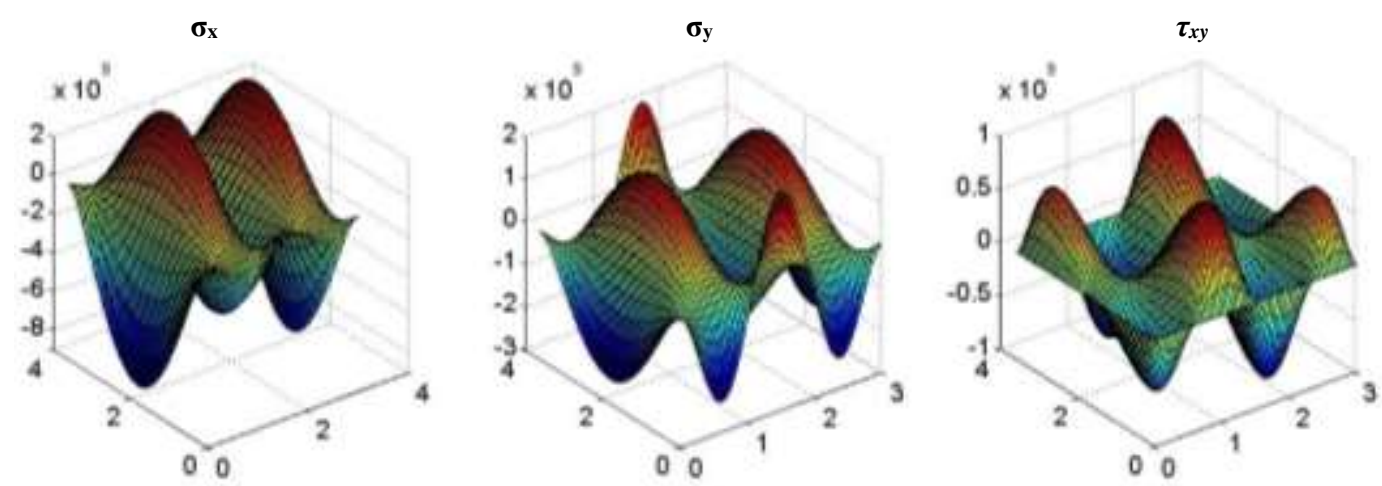

(a) The stress dynamic distribution at $0.5 \mathrm{~s}$
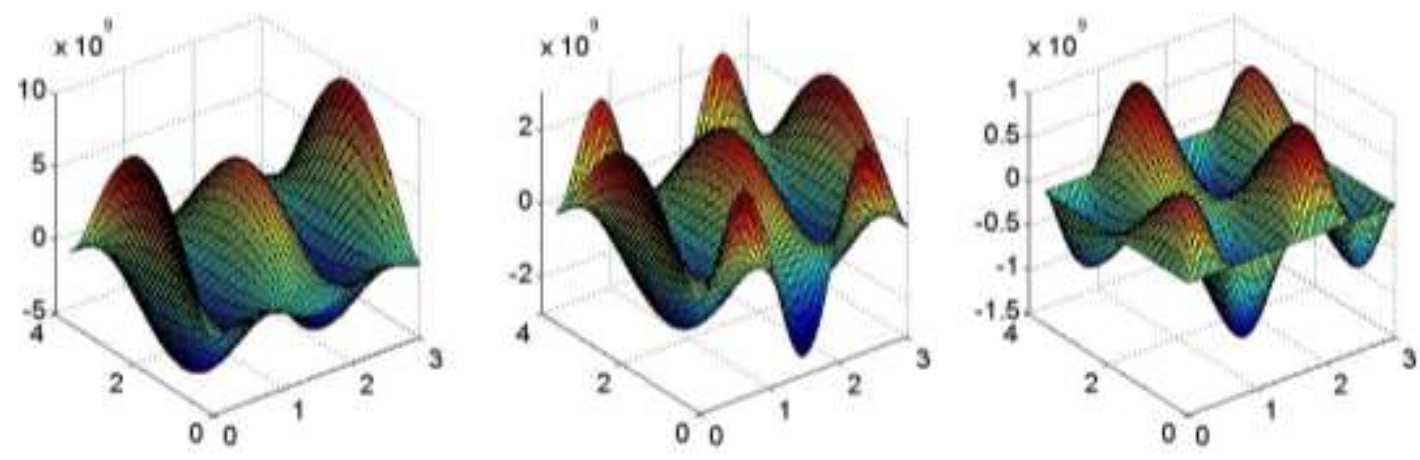

(b) The stress dynamic distribution at $1.5 \mathrm{~s}$

Fig. 8 The stress dynamic distribution of the $6^{\text {th }}$ mode at typical time

Similarly, the stress dynamic distribution of the $6^{\text {th }}$ mode of thin plate rock mass was drawn by taking the vibration state of typical time points $0.5 \mathrm{~s}$ and $1.5 \mathrm{~s}$ respectively, as shown in Fig. 8. It could be seen that: (1) the stress $\left(\sigma_{x}\right)$ mainly concentrated in the short central axis and the middle of the two long sides, which were symmetrical along the short center axis; (2) and the stress $\left(\sigma_{y}\right)$ concentrated areas were mainly distributed in four corners, long central axis and the middle of the four sides of thin plate, which were symmetrical along the short center axis; (3) the stress $\left(\tau_{x y}\right)$ concentrated areas were mainly distributed in the four corners and the middle of two short sides.

4.1.4 Dynamic distribution of the maximum shear stress $\left(\tau_{\max }\right)$

Based on the third strength criterion, the vibration states at typical time points $(0.49 \mathrm{~s}, 0.5 \mathrm{~s}, 1.5 \mathrm{~s}$ and $1.51 \mathrm{~s})$ were taken respectively, and the dynamic distribution of the maximum shear stress $\left(\tau_{\max }\right)$ of the $1^{\text {st }}$ mode was drawn, as shown in Fig. 9, and its maximum shear stress concentrated in the middle of the four sides, which was symmetrical along the long and short central axis. Similarly, 
taking the vibration state of typical time points $(0.5 \mathrm{~s}$ and $1.5 \mathrm{~s})$ respectively, the dynamic distribution of the maximum shear stress of the $5^{\text {th }}$ and $6^{\text {th }}$ modes were shown in Fig. 10 and Fig. 11. The maximum shear stress concentration area of the $5^{\text {th }}$ mode was mainly distributed in the long central axis and the middle of the two short sides which was symmetrical along the long central axis; and that of the $6^{\text {th }}$ mode in the short central axis and the middle of the two long sides, which was symmetrical along the short central axis.

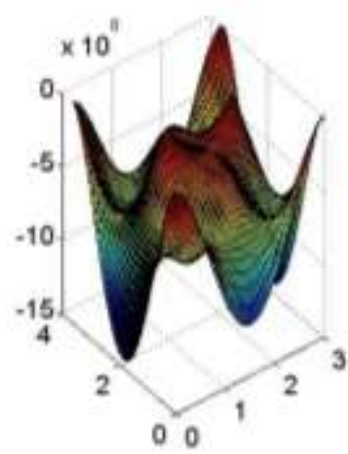

$0.49 \mathrm{~s}$

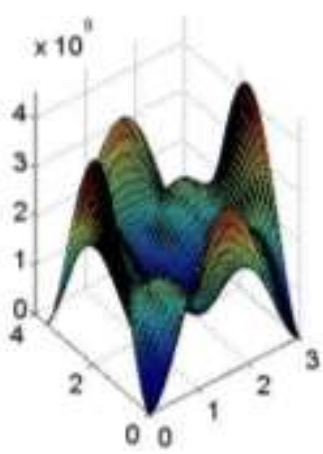

$0.5 \mathrm{~s}$

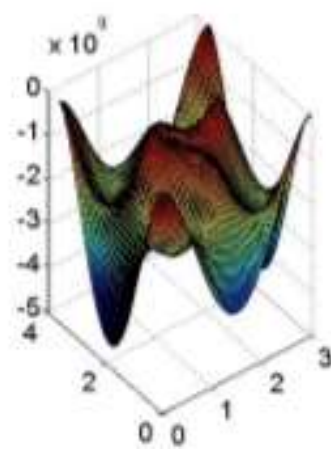

$1.5 \mathrm{~s}$

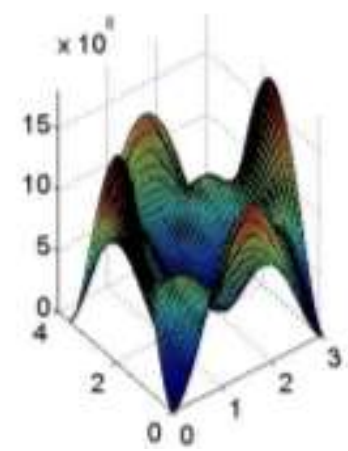

$1.51 \mathrm{~s}$

Fig.9 Dynamic distribution of the maximum shear stress $\left(\tau_{\max }\right)$ of the $1^{\text {st }}$ mode at typical time
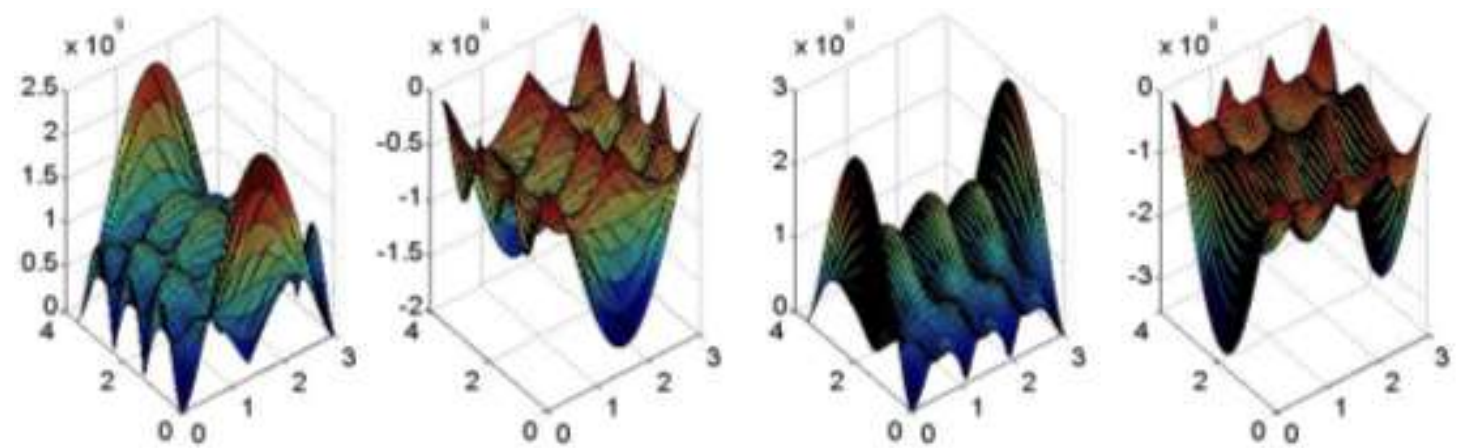

The stress $\tau_{\max }$ of $5^{\text {th }}$ at $0.5 \mathrm{~s} \quad$ The stress $\tau_{\max }$ of $5^{\text {th }}$ at $1.5 \mathrm{~s} \quad$ The stress $\tau_{\max }$ of $6^{\text {th }}$ at $0.5 \mathrm{~s}$ The stress $\tau_{\max }$ of $6^{\text {th }}$ at $1.5 \mathrm{~s}$

Fig. 10 Dynamic distribution of the maximum shear stress $\left(\tau_{\max }\right)$ of the $5^{\text {th }}$ and $6^{\text {th }}$ modes at typical time

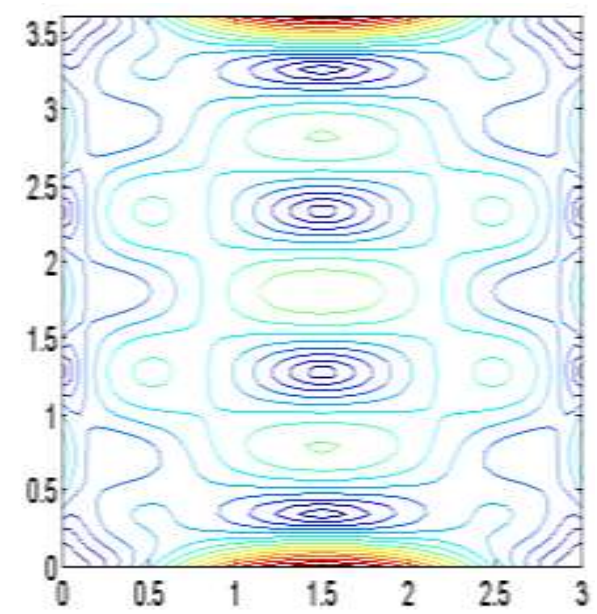

(a) the $5^{\text {th }}$ mode

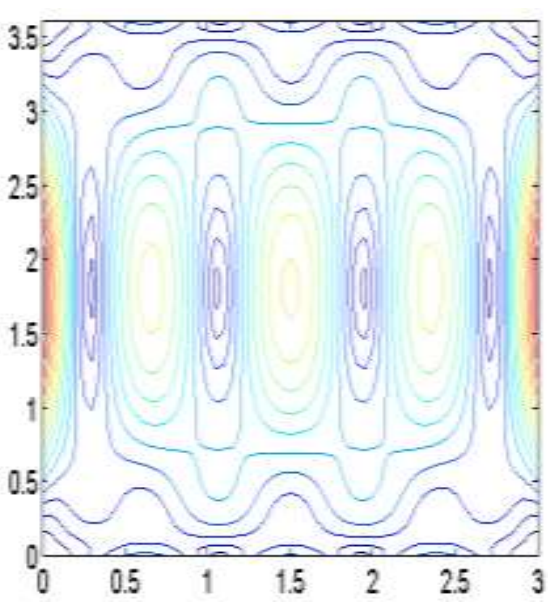

(b) the $6^{\text {th }}$ mode

Fig. 11 Contour map of the shear stress $\left(\tau_{\max }\right)$ of the $5^{\text {th }}$ and $6^{\text {th }}$ modes at $0.5 \mathrm{~s}$

4.2 Dynamic response of the thin plate rock mass under sustained triangular wave and impact wave 
Under sustained triangular wave and impact wave, the time harmonic vibration term $\varphi_{\mathrm{m}}(\mathrm{t})$ of effective modes about the $1^{\text {st }}, 5^{\text {th }}$ and $6^{\text {th }}$ orders were analyzed and their vibration patterns were shown in Fig. 12 and Fig. 13. It could be seen that: (1) the vibration periods of effective vibration modes about the $1^{\text {st }}, 5^{\text {th }}$ and $6^{\text {th }}$ orders of thin plate rock mass were about $1 \mathrm{~s}, 0.2 \mathrm{~s}$ and $0.12 \mathrm{~s}$ respectively, and that of the $5^{\text {th }}$ and $6^{\text {th }}$ modes tended to decrease gradually; (2) the amplitude of the 1st mode was the largest which took about $0.5 \mathrm{~s}$ to reach the peak; (3) The vibration laws of thin plate rock mass were similar under sustained regular triangular wave and impact wave, and the change of the $1^{\text {st }}$ mode vibration state was the most sharp, and the positive and negative alternation of its amplitude was the most frequent in the whole period, which had the most obvious effect on the vibration of the thin plate rock mass. The dynamic distribution of deflection, stress and maximum shear stress under sustained triangular wave and impact wave were similar to that of sustained rectangular wave.
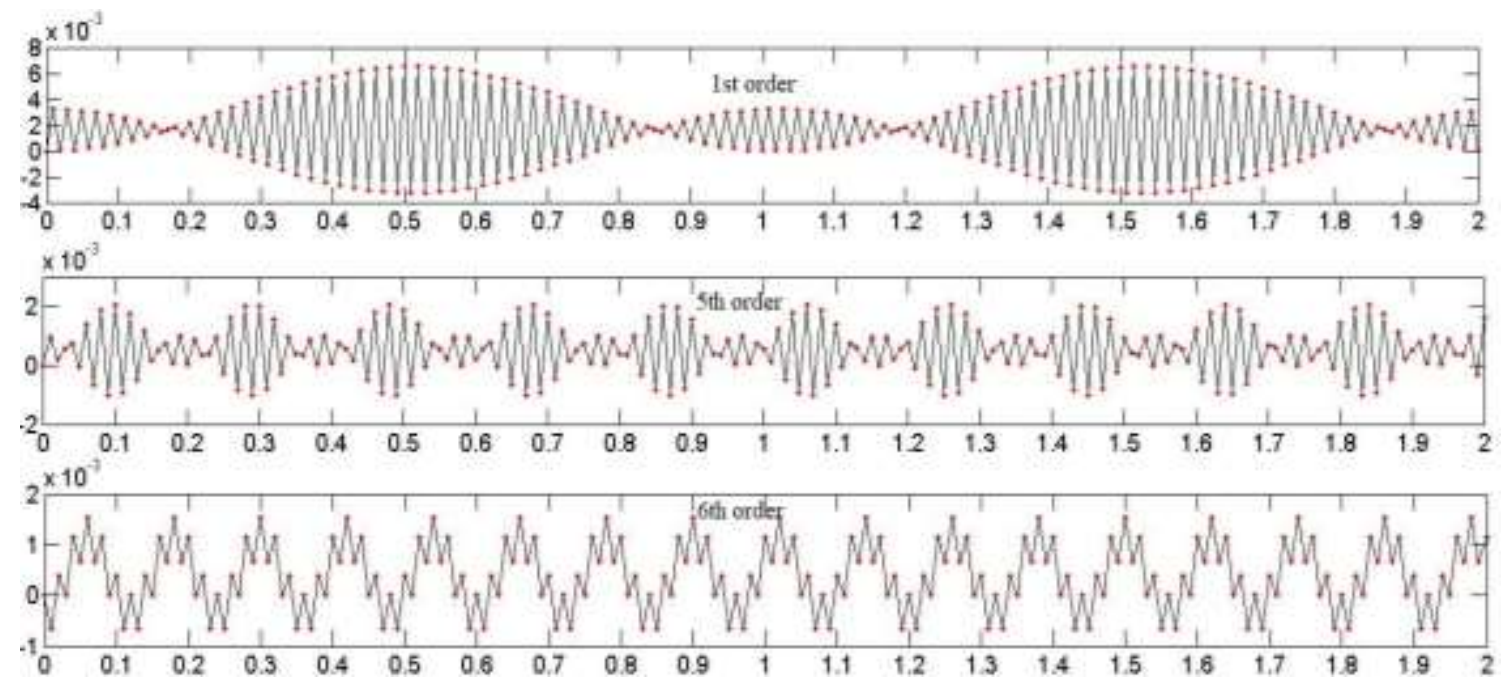

Fig. 12 the vibration of $\varphi_{\mathrm{m}}(\mathrm{t})$ of effective modes $\left(1^{\text {st }}, 5^{\text {th }}\right.$ and $6^{\text {th }}$ orders $)$ under sustained triangular wave
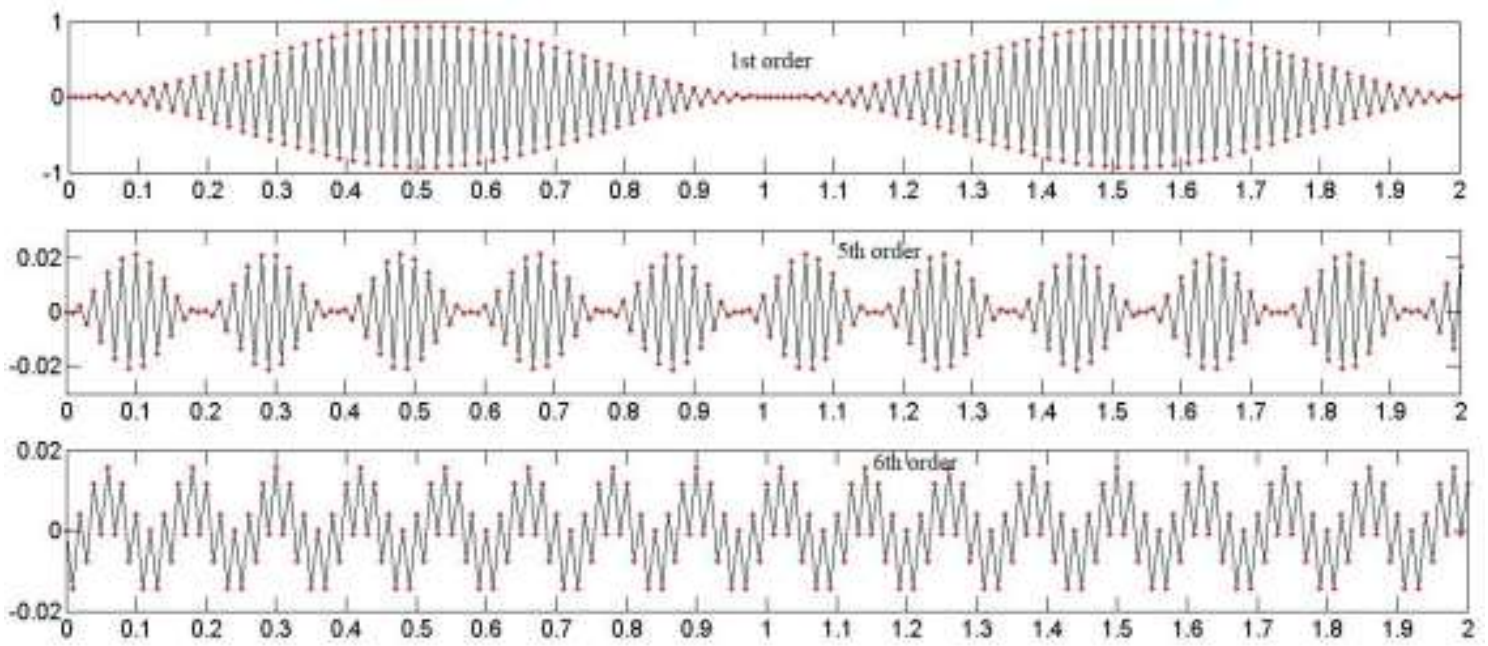

Fig. 13 the vibration of $\varphi_{\mathrm{m}}(\mathrm{t})$ of effective modes $\left(1^{\mathrm{st}}, 5^{\text {th }}\right.$ and $6^{\text {th }}$ orders $)$ under sustained impact wave

\section{Discussion on dynamic damage and failure mechanism of the thin plate rock mass C-C-C-C under sustained dynamic load}

5.1 Theoretical analysis of the dynamic damage and failure mechanism

From Fig. 6 to Fig. 8, it could be concluded that in the central area of the thin plate rock mass, the 
stress $\sigma_{\mathrm{x}}$ of the $1^{\text {st }}$ and $6^{\text {th }}$ effective mode were greater than the stress $\sigma_{\mathrm{y}}$, and the stress $\sigma_{\mathrm{y}}$ of the $5^{\text {th }}$ effective mode was greater than the stress $\sigma_{\mathrm{x}}$, and the shear stress was relatively small, which show that the tensile failure is the main failure pattern in the central area of the thin plate.

The stress $\sigma_{\mathrm{x}} 、 \sigma_{\mathrm{y}}$ and $\tau_{\max }$ concentrated in the middle of the four sides of the thin plate rock mass together; the shear stress $\tau_{\mathrm{xy}}$ of the 1 st, 5th and 6th modes and stress $\sigma_{\mathrm{y}}$ of the $6^{\text {th }}$ mode concentrated at four corners. Therefore, it could be obtained that the failure of the four sides of the thin plate was mainly caused by the combined action of tensile and shear stress, and their failure pattern was mainly tensile-shear failure, and that of four corners was mainly shear failure.

In the area outside the four sides and four corners of the thin plate rock mass, the maximum shear stress of the $1^{\text {st }}$ mode was relatively small, and that of the 5th and 6th modes concentrated along the long central axis and short central axis of the thin plate respectively (Fig. 10 and Fig. 11). Therefore, it could be inferred that the crack propagated into the main crack along the long central axis and a secondary crack along the short central axis of the thin plate rock mass under sustained dynamic load.

5.2 Numerical simulation of the dynamic damage and failure

Based on LS-DYNA, the PLASTIC_KINEMATIC material model was used to simulate and analyze the process of damage and failure of the thin plate rock mass C-C-C-C under sustained dynamic load. The short side of the model is horizontal and the long side is vertical. The model size is $3 \mathrm{~m} \times 3.6 \mathrm{~m}$, Cowper Symonds model is used to describe the yield process of rock mass, and the sustained impact load acts uniformly on the surface of rock mass.

The results of numerical simulation of the dynamic damage and failure process of the thin plate rock mass could be shown as follows (Fig. 14): firstly, plate cracks occurred in the middle of the four sides and four corners, and these cracks would propagate rapidly along the boundary of the thin plate rock mass(Fig. 14(a)), which was consistent with Fig. 6 to Fig. 8; and then, plate cracks occurred in the central area of the thin plate rock mass and the main develop tendency of these cracks was outward along the long central axis, and that also tended to expand outward along the short central axis (Fig. 14(b) and Fig. 14(c)), which was consistent with Fig. 9 to Fig. 10. And it is obvious that there were many small cracks along the direction of short side (horizontal direction ) on the plane of the thin plate.

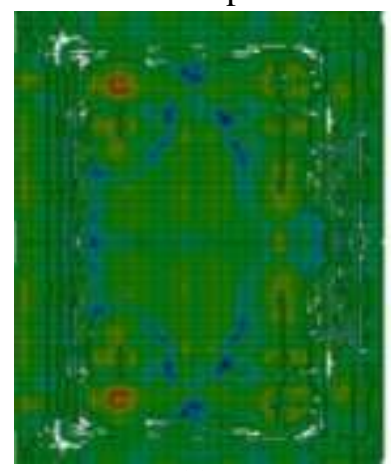

(a)

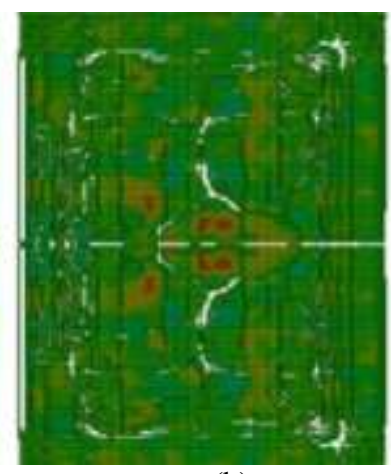

(b)

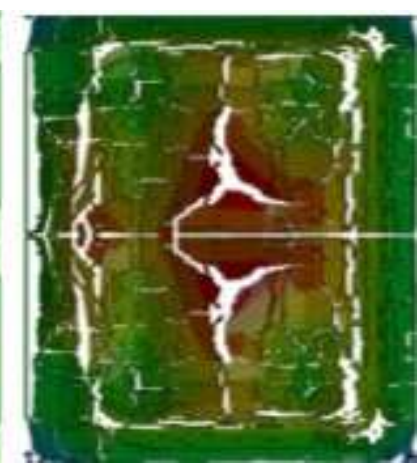

(c)

Fig. 14 Dynamic damage and failure process of the thin plate rock mass

From this, we could infer that the initial failure position of the thin plate rock mass C-C-C-C under sustained dynamic load, to a large extent, could be determined by the $1^{\text {st }}$ effective mode, such as the middle of the four sides, four corners and central area of the thin plate; and the development direction and trend of the cracks could be determined by the $5^{\text {th }}$ and $6^{\text {th }}$ effective modes.

7.3 Comparison of static damage and dynamic damage of thin plate rock mass C-C-C-C

The failure patterns of thin plate rock mass $\mathrm{C}-\mathrm{C}-\mathrm{C}-\mathrm{C}$ with thickness of $2 \mathrm{~cm}$ and critical thickness 
of $4.5 \mathrm{~cm}$ were studied under static load by the simulation experiment device for roof breakage in goaf, as shown in Fig. $15^{[26]}$. The results showed that: (1) under uniform static load, the four sides of the thin plate were subjected to the combined action of shear and tensile stress, and the shear stress was the main factor which made the four sides of the plate produce tensile-shear failure and form "O" ring. (2) the tensile failure occurred in the central area of the thin plate and formed one main vertical crack, which continuously propagated along the long axis, split into " $\mathrm{X}$ " type crack at a certain position and extended to the four corners of the short sides, and finally formed "O-X" failure pattern. (3) and it was obvious that there was a horizontal cracks along the short central axis of the thin plate with critical thickness of $4.5 \mathrm{~cm}$, which made the thin plate formed "O-*⿻丷木' failure pattern.

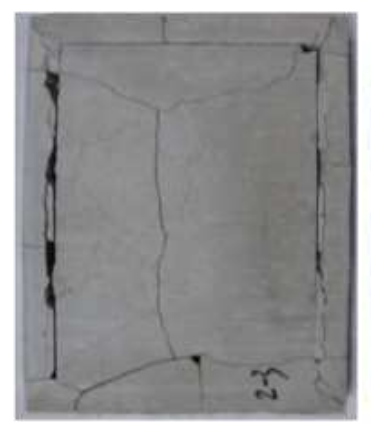

(a) thin plate rock mass with thickness of $2 \mathrm{~cm}$
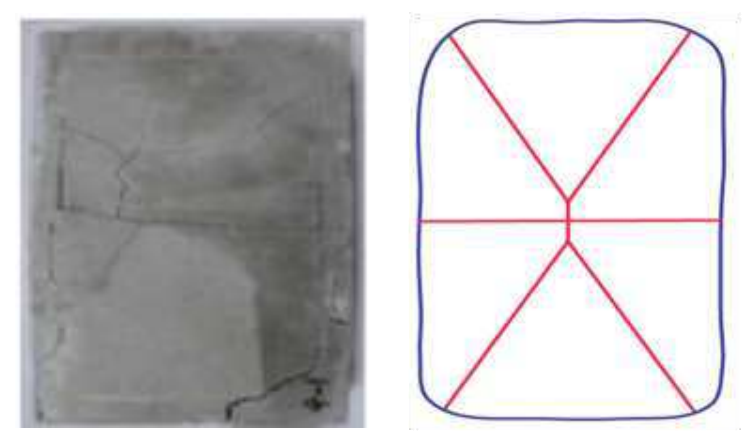

(b) thin plate rock mass with critical thickness of $4.5 \mathrm{~cm}$

Fig. 15 the failure pattern of thin plate rock mass C-C-C-C under static load

According to the Fig. 14, under sustained dynamic load, the four sides of the thin plate rock mass C-C-C-C occurred tensile-shear failure, and the four corners shear failure. The tensile failure occurred in the central area of the thin plate to form one main crack propagating along the long axis and a secondary crack extending along the short central axis, which finally formed "O-十" failure pattern; and along the short side, there were many small cracks on the plane of the thin plate rock mass.

\section{Conclusions}

(1) Based on the dual equation of Hamilton system and Duhamel's integral, the mechanical model of homogeneous rectangular thin plate rock mass was established under uniform dynamic load. The effective vibration modes (the $1^{\text {st }}, 5^{\text {th }}$, and $6^{\text {th }}$ modes) and their frequencies of thin plate rock mass C-C-C-C were obtained.

(2) Under sustained dynamic load, the change of the 1st mode vibration state was the most sharp, and the positive and negative alternation of its amplitude was the most frequent in the whole period, which had the most obvious effect on the vibration of the thin plate rock mass.

(3) Under sustained dynamic load, plate cracks firstly occurred in the middle of the four sides and four corners; and then plate cracks occurred in the central area of the thin plate which was outward along the long and short central axis. The initial failure position, to a large extent, could be determined by the $1^{\text {st }}$ effective mode, and the development direction and trend of the cracks could be determined by the $5^{\text {th }}$ and $6^{\text {th }}$ effective modes.

(4) Under sustained dynamic load, the four sides of the thin plate rock mass occurred tensile-shear failure, and the four corners shear failure. and then the tensile failure occurred in the central area of the thin plate to form one main crack propagating along the long axis and a secondary crack 
extending along the short central axis, which finally formed "O-十" failure pattern; and along the short side, there were many small cracks on the plane of the thin plate rock mass.

\section{Data Availability}

The data used to support the findings of this study are available from the corresponding author upon request.

\section{Conflicts of Interest}

The authors declare that they have no conflicts of interest.

\section{Acknowledgements}

This study was financially supported by National Natural Science Foundation of China (51804311, 52064046), China National University of Mining and Technology (Beijing) State Key Laboratory of Deep Geotechnical Mechanics and Underground Engineering Open Fund Project (SKLGDUEK1818), and the Fundamental Research Funds for the Central Universities (2020YJSAQ13)

\section{References}

[1] Xu D P, Feng X T, Chen D F, et al. Constitutive representation and damage degree index for the layered rock mass excavation response in underground openings. Tunnelling and Underground Space Technology, 2017, 64: 133-145.

[2] Wang P T, Cai M F, Ren F H. Anisotropy and directionality of tensile behaviours of a jointed rock mass subjected to numerical Brazilian tests. Tunnelling and Underground Space Technology, 2018, 64: 133-145.

[3] Liu YS, He CS, Fu HL, etal. Study on dynamic and static mechanical properties and failure mode of layered slate, Journal of Railway Science and Engineering, 2020,17(11):2789-2797.

[4] Wu GP, Shen WW, Cui K, et al. Degradation behavior and mechanism of slate under alternating conditions of freeze-thaw and wet-dry. Journal of Central South University, 2019, 50(6): 1392-1402.

[5] Liu YS, Wang SM, Yan SJ, et al. Properties and failure mechanism of layered sandstone based on acoustic emission experiments. Journal of Central South University (Science and Technology), 2019, 50(6): 14191427.

[6] Zhou PF, Shen YS, Zhao JF, et al. Research on disaster-induced mechanism of tunnels with steeply dipping phyllite strata based on an improved ubiquitous-joint constitutive model. Chinese Journal of Rock Mechanics and Engineering, 2019, 38(9): 1870-1883

[7] Song DZ. Study on evolution process and energy dissipation characteristics of rockburst, China University of Mining and Technology, 2012

[8] Guo PK. Study on the development mechanism of spallation in coal and gas outburst [D]. China University of Mining and Technology, 2014

[9] FAIRHURST C, COOK N G W. The phenomenon of rock splitting parallel to the direction of maximum compression in the neighborhood of a surface, Proe First Congr Intemat Soc Rock Mech. Lisbon, 1966: 687-692

[10] Li XB, Du K, Li DY. True triaxial strength and failure modes of cubic rock specimens with unloading the minor principal stress. Rock Mechanics and Rock Engineering, 2015, 48(6):2185-2196.

[11] Hou ZS, Gong QM, Sun ZH. Primary failure types and their failure mechanics of deep buried and intact marble at Jinping II hydropower station. Chinese Journal of Rock Mechanics and Engineering, 2011, 30(4): 
$727-732$.

[12] CAI M. Influence of intermediate principal stress on rock fracturing and strength near excavation boundaries- Insight from numerical modeling. International Journal of Rock Mechanics and Mining Sciences, 2008, 45(5): 763-772

[13] Liu N, Zhu WS, Yu GM, et al. Research on mechanical model of thin plate and splitting failure criterion for surrounding rocks with high geostress. Chinese Journal of Rock Mechanics and Engineering, 2008, 27(S1): 3173-3179.

[14] LI XJ. Experimental and theoretical research on the mechanism of splitting failure in deep cavern. Jinan: Shandong University, 2007

[15] ORTLEPP W D. The behaviour of tunnels at great depth under large static and dynamic pressures. Tunnelling and Underground Space Technology, 2001, 16(1): 41-48.

[16] Feng F, Li XB, LI Di Y, etal. Mechanism and control strategy of buckling rockbursts of orthotropic slab. Chinese Journal of Geotechnical Engineering 2017;39(7):1302-1311.

[17] Li F, Bi MX, Tian J, et al. The Dynamic Damage Mechanisms and Failure Modes of Coal-Rock Masses under the Action of High Order P-Waves. Shock and vibration 2018;5:1-11.

[18] Su GS, Hu LH, Feng XT, etal. True triaxial experimental study of rockburst process under low frequency cyclic disturbance load combined with static load. Chinese Journal of Rock Mechanics and Engineering, 2016, 35(7): 1309-1322

[19] Chang WB, Fan SW, Zhang L. A model based on explosive stress wave and tectonic coal zone which gestate dangerous state of coal and gas outburst. Journal of China Coal Society, 2014, 39(11): 2226-2231.

[20] Cai F, Liu ZG, Luo Y. Propagation and attenuation characteristics of stress waves generated by explosion in high-gas coal-beds. Journal of China Coal Society, 2014, 39(1): 110-114.

[21] Dou LM, He XQ, Ren T. Mechanism of coal-gas dynamic disasters caused by the superposition of static and dynamic loads and its control technology. Journal of China University of Mining \& Technology, 2018,47(1):48-59.

[22] Luo MK, Fan CJ, Li S, et al. Failure criteria of the geological dynamic system of coal and gas outburst. Journal of China Coal Society, 2018,47(1):137-144.

[23] Bao SY, Deng ZC. A General Solution of Free Vibration for Rectangular Thin Plates in Hamilton Systems. Journal of Dynamics and Control 2005; 3(2): 10-16.

[24] Li R. Wang B. Li P. Hamiltonian system-based benchmark bending solutions of rectangular thin plates with a corner point supported. International Journal of Mechanical Sciences 2014;85:212-218.

[25] Li F, Dong XH, Wang Y, et al. The Dynamic Response and Failure Model of Thin Plate Rock Mass under Impact Load. Shock and Vibration, 2021(11), 1-15

[26] Zuo JP, Yu ML, Hu SY, et al. Experimental investigation on fracture mode of different thick rock strata. Journal of Mining and Strata Control Engineering, 2019,1(1): 013007 